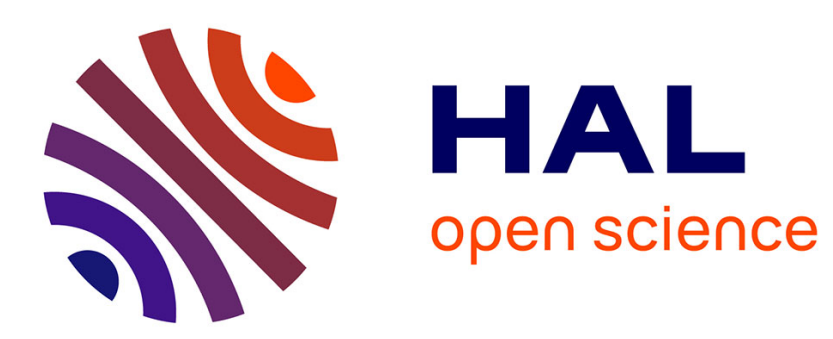

\title{
The influence of theoretical mathematical foundations on teaching and learning: a case study of whole numbers in elementary school
}

Christine Chambris

\section{- To cite this version:}

Christine Chambris. The influence of theoretical mathematical foundations on teaching and learning: a case study of whole numbers in elementary school. Educational Studies in Mathematics, 2018, 97 (2), pp.185-207. 10.1007/s10649-017-9790-3 . hal-02270063

\section{HAL Id: hal-02270063 \\ https://hal.science/hal-02270063}

Submitted on 23 Aug 2019

HAL is a multi-disciplinary open access archive for the deposit and dissemination of scientific research documents, whether they are published or not. The documents may come from teaching and research institutions in France or abroad, or from public or private research centers.
L'archive ouverte pluridisciplinaire HAL, est destinée au dépôt et à la diffusion de documents scientifiques de niveau recherche, publiés ou non, émanant des établissements d'enseignement et de recherche français ou étrangers, des laboratoires publics ou privés. 


\title{
Author's Name
}

Christine Chambris

\section{Title}

The influence of theoretical mathematical foundations on teaching and learning: A case study of whole numbers in elementary school.

\section{Affiliation}

Laboratoire de didactique André Revuz, Université de Cergy-Pontoise, UPD, UPEC, U Artois, U Rouen Normandie, France

\section{Address}

Université Paris Diderot,

UFR de Mathématiques- Case 7018

Laboratoire de didactique André Revuz

75205 PARIS Cedex 13, France

Email: christine.chambris@u-cergy.fr

Phone (Office): +33157279156

Phone (Mobile): +33614527401

\section{Acknowledgment}

This article is based on a paper that was presented at the pre-conference for the $23^{\text {rd }}$ ICMI study on Whole Number Arithmetic in Macau (China), in June 2015.

\begin{abstract}
This paper examines the existence and impact of theoretical mathematical foundations on the teaching and learning of whole numbers in elementary school in France. It shows that the study of the New Math reform which was eventually itself replaced in the longer term - provides some keys to understanding the influence of mathematical theories on teaching and learning. The paper studies changes related to place value, a notion that was deeply impacted by the introduction of numeration bases other than ten in 1970, and their subsequent removal in the 1980s. What the author terms 'numeration units' (ones, tens, hundreds, thousands, etc.) and 'powers-of-ten written in figures' $(1,10,100,1000$, etc.) are key tools for describing and understanding changes. The author identifies two theories that have formed the basis for place value teaching in the $20^{\text {th }}$ century, and examines some aspects of their influence. The paper also addresses epistemological issues in the relation between academic mathematics and school mathematics, and highlights the role of units in the teaching of basic arithmetic.
\end{abstract}

\section{Keywords}

New Math reform; relation between school and academic mathematics; didactic transposition; place value; numeration unit; unit 


\section{Introduction}

The discussion document of the $23^{\text {rd }}$ International Commission on Mathematical Instruction (ICMI) study on whole number arithmetic recalls the important role of mathematicians in the foundational processes of mathematics teaching and learning, and quotes Felix Klein in 1923:

I believe that the whole sector of Mathematics teaching, from its very beginnings at elementary school right through to the most advanced level research, should be organised as an organic whole. It grew ever clearer to me that, without this general perspective, even the purest scientific research would suffer, inasmuch as, by alienating itself from the various and lively cultural developments going on, it would be condemned to the dryness which afflicts a plant shut up in a cellar without sunlight (as cited in ICMI, 2014).

Klein himself, as well as several outstanding mathematicians such as Lebesgue and Freudenthal, was involved in epistemological analyzes with didactical applications. Between the mid-1950s and the mid-1970s, a wind of change blew through the world and modernized mathematics education; the aim was "to bring school mathematics closer to the academic mathematics of the twentieth century" (Kilpatrick, 2012, p. 563). This period stimulated significant research into the theoretical foundations of teaching elementary school mathematics (e.g., Freudenthal, 1973; Griesel, 2007; Wittman, 1975). Otte (2011) uses two questions to illustrate the controversy that emerged in many countries during this period: "What do we say to a young child, asking if concepts like force or pressure really exist?" (p. 314) from the psychologist Bruner (a supporter of the reform); and "the real problem is not that of rigor, but the problem of the development of meaning, of the existence of mathematical objects" (p. 314) from the mathematician Thom (a critic of the reform). Otte himself calls for "alternatives to settheoretical foundationalism [for teaching]" (p. 314) because "Concepts or theories have to be accepted as real before we can ask for their meaning" (p. 325). In practice, new mathematics took various forms: for example, although Freudenthal is often said to have prevented the introduction of New Math into the Netherlands, he nevertheless led the modernization of mathematics teaching there.

Although it is natural to assume that academic mathematics should have an important role in school mathematics, the relation between the two is complex. This paper aims to provide a better understanding of one facet of this relation, namely the influence of theoretical mathematical foundations on teaching and learning in elementary school. It examines the paradigmatic case of whole numbers in France, the country where the eminent mathematician Lichnérowicz headed the New Math reform commission (1966-1973).

\section{Background}

How can we study the existence and impact of mathematical foundations on the teaching and learning of whole numbers in elementary school? 


\subsection{A historical perspective}

\subsubsection{New Math}

New Math (Furinghetti, Menghini, Arzarello, \& Giacardi, 2008; Gispert, 2010; Kilpatrick, 2012) was an international phenomenon that took place between mid-1950s and mid-1970s in the Cold War context. It impacted mathematics teaching, from elementary school to university level, in many countries. As Kilpatrick (2012) claims: "In no country did school mathematics return to where it had been before the New Math movement began: The pendulum is not a suitable metaphor for curriculum change" (p. 569). One of the major aims of the reform was the teaching of new math, including renewing the theoretical foundations of teaching. A particular concern was that psychological aspects of learning and child development should be taken into account. Several famous mathematicians, such as Jean Dieudonné, played an active role, and the psychologists Jean Piaget and Jerome Bruner contributed.

\subsubsection{Previous work in the French context}

As changes to the curriculum are often slow and therefore difficult to identify, periods of stability provide the best contrast. Several works (e.g., Bronner, 2007; Chambris, 2010; Harlé, 1984; Neyret, 1995) have addressed the evolution of teaching numbers in France in the $20^{\text {th }}$ century. They lead to the identification of three main periods, and two transitional ones: The stable, classical, period (until the 1940s); the highly turbulent period of the New Math reform (1970-1980) ${ }^{1}$; ongoing evolution during the contemporary period (1995-2012); and two transitional periods before and after the New Math reform. Several texts were very influential: notably, the treatises by Bezout and Reynaud (the classical period) - for teacher education - and the textbook Math et calcul (in the 1980s).

\subsection{Refining the subject: changes in numeration}

New Math saw the introduction of two major changes in the early study of whole numbers: set theory, which reflects the impact of contemporary mathematics, and numeration bases other than ten (hereafter called bases) that were introduced in order for children to understand base ten principles. The latter reflects the impact of psychology:

For while, many virtues have been discovered for numbers to the base 10, students cannot appreciate such virtues until they recognize that the base 10 was not handed down from the mountain by some mathematical God. It is when the student learns to work in different number bases that the base 10 is recognized for the achievement that it is. (Bruner, 1966, pp. 71-72)

It seems that, although much has been written about the mathematical foundations of whole numbers, those of numeration have received less attention, both at the time of the New Math and later. For example, Bednarz and Janvier (1982) indicate they notably based their research on the "mathematical definition [of numeration]" without giving further details about this definition.

\footnotetext{
${ }^{1}$ In France, the New Math elementary school syllabus was published in 1970. This was followed by a counter-reform, with syllabi published between 1977 and 1980 (depending on the class level).
} 
This study focuses on numeration. The French New Math syllabus of 1970 introduced elements of set theory and bases (which were removed in the 1980s). The main goal of the present study is to examine the influence, if any, of the theoretical mathematical foundations of whole number numeration on teaching and learning. Following previous work, a time span that encompasses the New Math reform was chosen, as this makes it possible to characterize the effects of several different theoretical foundations. The questions that arise are: What were the mathematical theoretical foundations of numeration in different periods of time: specifically, before, during and after the New Math? Have they influenced teaching and learning, and, if so, how?

\subsection{Several systems of numeration}

A numeration system is a system for representing numbers. Such systems are also needed for computation. Nowadays, in France, as in many countries throughout the world, elementary school students learn two whole number numeration systems: one for writing (e.g., 9, 19, 90); and another for speaking (e.g., nine, nineteen, ninety). The former has syntactic characteristics and it is used internationally; the latter is specific to a language with its own grammatical and syntactical characteristics (e.g., Fuson, 1990).

Anglophonic literature speaks of 'place value', while the Francophonic literature refers to 'positional notation' (word-for-word translation) in writing numbers. It seems that neither the Anglophonic nor the Francophonic educational literature has established a name for the units used in numeration (e.g., the ones, tens, hundreds and thousands used in base ten). For instance, Thanheiser (2009) speaks of "reference units" (p. 263), while Fuson (1990) refers to "multiunits" (p. 344). In France, Chambris (2008) suggests "unités de la numération" (p. 404) (numeration units in English). Here, they are referred to as O, T, H and Th respectively. Hence, the teaching of numeration embeds three semiotic systems: number names, positional notation, and numeration units.

To help to compare France to other countries, and to take a prudent approach with regard to the international literature, here we indicate some specificities of number names in French. Unlike most East Asian languages, many European languages give irregular names to whole numbers (Fuson, 1990). In English, unlike French, the names given to powers of ten are the same as those of the units (Table 1). Furthermore, in French, the names of the $2^{\text {nd }}, 3^{\text {rd }}$, and $4^{\text {th }}$ numeration units for whole numbers are little-used in everyday language.

Table 1 Number names and numeration units names in French and English

\begin{tabular}{lll}
\hline French & & English \\
\hline Number & Numeration unit & Numeration unit and number \\
\hline un (une) & unité & One \\
dix & dizaine & Ten \\
cent & centaine & Hundred \\
mille & millier & Thousand \\
\hline
\end{tabular}

\subsection{Theoretical framework}

\subsubsection{The theory of didactic transposition}

The theory of didactic transposition (TDT) (Barbé, Bosch, Espinoza, \& Gascón, 2005; Chevallard, 1985) (Fig. 1) was developed in the early 1980s. It underlined the institutional relativity of knowledge, beginning with the 
analysis of the introduction of academic mathematics into school mathematics during the New Math in France. Knowledge produced by scholarly institutions was reconstructed by educational institutions in order 'to be taught', before being prepared and actually taught by teachers. Scholars (e.g., Castela \& Romo, 2011) expanded didactic transposition to other kinds of knowledge (e.g., expert vocational knowledge) - termed here reference knowledge - used as a reference point by educational institutions.

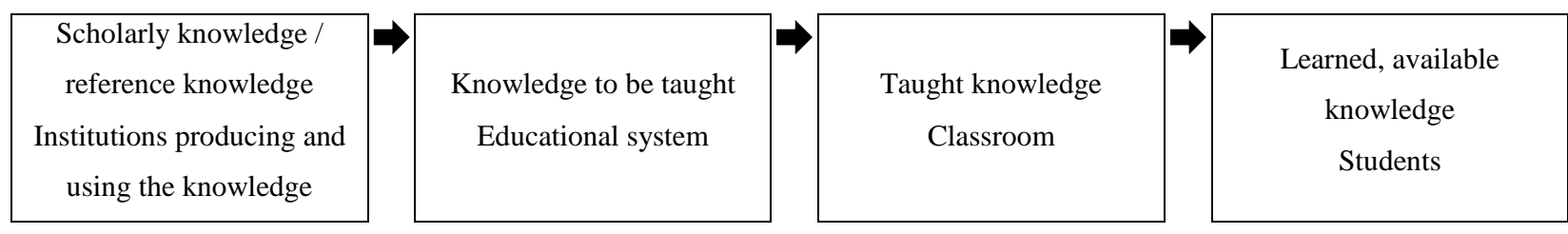

Fig. 1 The didactic transposition process

Although he does not refer to TDT, Ernest (2006) describes how the "mathematical theory" (p. 72) "formulated by mathematicians" (p. 72) is transformed into the "planned mathematics curriculum" (p. 72): "a selection is made of some target mathematical theory from the totality of publicly available mathematical knowledge. Given this selection, elements of a mathematical theory are recontextualised into a school mathematics topic." (p. 73). Furthermore, he identifies four stages in the transformation of semiotic systems in school mathematics, which are similar ${ }^{2}$ to those of TDT (Fig. 1).

\subsubsection{The Anthropological Theory of the Didactic}

Didactic transposition places didactic issues at the institutional level, beyond the characteristics of individuals working within a given institution. School mathematics found in textbooks and syllabi - at a given place and time - is considered as an institution, as is classroom practice (where teacher and students share work habits). The Anthropological Theory of the Didactic (ATD) (Chevallard, 1997) extended TDT. It introduced the metaphor of the institutional ecology of knowledge, which made it possible to study long-term teaching and learning processes (Arzarello \& Bartolini-Bussi, 1998) based on epistemological analyses of content and answer questions such as: What lives in a given institution? With who? What does not live? Why? A basic ATD tool is the notion of praxeology. This word indicates that practice (praxis) and the discourse about practice (logos) necessarily work hand-in-hand. ATD postulates that any human practice (notably that of mathematics) in a given institution, can be described in term of praxeologies (see also Bergé, 2008). There are four components (4 Ts): a Type (T) of tasks (a set of similar problems); a Technique ( $\tau$ ) (a way of doing tasks of the same type); Technology $(\theta)$ that justifies the technique; and Theory $(\Theta)$ that legitimates the technology.

We take the imaginary example of a second-grade textbook, where the column addition of two numbers is taught with one-to-three digit numbers, with or without re-grouping. This would be a type of task (T) for this institution, and the technique $(\tau)$ would be as follows. Consider: $48+176$. Write the two numbers, one under the other. Align the digits: put the ones below the ones; the tens below the tens; and the hundreds below the hundreds, if any. Then add each upper digit to the lower, from right to left as follows: 6 and 8 is 14, write down 4 and carry $1 ; 8$ and 1 is $9 ; 9$ and 7 is 16 ; write down 6 and carry $1 ; 1$ and 1 is 2 . Hence, for each step, the student

\footnotetext{
2 The wording is somewhat different: e.g., 'scholarly knowledge' corresponds to 'mathematical theory', while 'knowledge to be taught' corresponds to 'the planned mathematics curriculum'.
} 
must check whether the sum is greater than ten when performing the addition. If so, there is a 'carry' and she or he must write down the ones digit, and insert the tens digit above the left-hand-side digit. The technology $(\theta)$ provides the rationale for the algorithm and it relies on: 1) interpreting each digit as an amount of ones, tens or hundreds; 2) adding the amount of ones, tens and hundreds separately; and 3) the relations: 1 ten $=10$ ones, and 1 hundred $=10$ tens to justify the 'carry'. The technique may require an intermediate task: 'compare a number with ten'. The theory $(\Theta)$ encompasses the ways numbers are formed, as well as aspects of addition.

A perceptible object used in a praxeology is called an ostensive object (Bosch \& Chevallard, 1999). The set of praxeologies that involve a given ostensive object is called its instrumental value. In the example above, in the technique, the ostensive objects 'tens' and 'hundreds' are instruments used to locate digits. In the technology, they are used to interpret digit-values, count each type of units and convert, if need be. The 'meaning' created by the institutional uses of an ostensive object is termed its semiotic value.

In the institutional approach, knowledge is modeled by "prevailing mathematical praxeologies in the institutions considered" (Bosch, Gascon, \& Trigueros, 2017, p. 43) and "personal [learnt] praxeologies are a reflection, more or less distorted, of the corresponding institutional praxeologies" (p. 43).

\subsection{Research questions}

The process of didactic transposition makes it possible to identify reference knowledge - including theoretical mathematical foundations - and trace it in teaching. Within the ATD framework, the way a topic is taught and learned in a given institution can be described in terms of praxeologies. The mathematical foundation should first appear as a part of theoretical component. Here, we argue that its impact on tasks, techniques, or technologies can be more easily characterized by contrasting praxeologies with different theoretical components. Hence, our question can be rephrased as follows: Are there traces of the transposition of numeration reference knowledge in different time periods? Are there any visible changes in tasks, techniques, or technologies from one period to another that might be attributed to changes in the theoretical component?

\subsection{Data and methodology}

Although the national elementary syllabus is compulsory in France, there are neither national nor accredited textbooks. Furthermore, the syllabus has changed many times: in 1882, 1923, 1945, 1970, 1977-1980, 1985, 1991, 1995, 2002, and 2008. In some cases, instructions that describe how to teach a subject have been provided. Textbooks are updated when the national syllabus changes, but sometimes this is limited to the addition of a stamp on the cover saying "in line with the new syllabus". Teachers are not required to use updated textbooks, or any textbook at all. Budget for the textbooks is provided by the city council. Schools do not always have a budget to buy new ones when the syllabus changes.

French syllabi are not targeted at a specific grade, but encompass two, or even three grades. Moreover, they do not always fully specify which range of whole numbers should be taught at different stages, although partial information is usually provided. It is clear that since 1923, the numbers up to 100 have been taught in first grade. In the period 1945-1991, the numbers up to 10000 were taught in second and third grades, while between 1991 and 2012, the numbers up to 1000 were taught in second grade. It appears that the core ideas regarding place value are taught in second and third grades. 
The data used here includes the national syllabi (and any teacher instructions) for elementary school (grades one through five), second- and third-grade textbooks, and resources for teacher education (Table 2). In order to select the most influential texts, the National Library of France's catalog, which identifies textbooks, was consulted. For the period 1900-1970, textbooks that had several editions were selected. For the period 1978-1995, "Math et calcul” was selected (Neyret, 1995). It was also selected for the New Math period, with two other textbooks which had only one edition (like most of the textbooks published in this period). For the period 1995-2004, publishers provided information about the most popular textbooks, and an innovative series was added. From 2005 onwards, popular textbooks were recommended by teachers. Concerning teacher education, the selected texts included: 1) teachers' guides combined with selected textbooks; 2) the treatises by Bezout and Reynaud; and 3) teachers' guides from an influential series authored by the Elementary Math Research Team at the National Institute of Pedagogy (ERMEL).

Table 2 Selection of textbooks and resources for teacher education

\begin{tabular}{|c|c|c|c|c|c|}
\hline & \multicolumn{5}{|c|}{ Time period and name of the period (if any) } \\
\hline & $\begin{array}{c}\text { 1900-1950: } \\
\text { Classical }\end{array}$ & $1950-1970$ & $\begin{array}{l}\text { 1970-1977: } \\
\text { New Math }\end{array}$ & $\begin{array}{l}\text { 1977-1995: } \\
\text { Early Post- } \\
\text { Reform }\end{array}$ & $\begin{array}{l}\text { 1995-2012: } \\
\text { Late post- } \\
\text { reform }\end{array}$ \\
\hline $\begin{array}{l}\text { Number of textbooks for (gr.2, gr.3, } \\
\text { gr.2\&3) }\end{array}$ & $(4,4,5)$ & $(3,3,1)$ & $(3,3,0)$ & $(0,2,0)$ & $(0,12,0)$ \\
\hline $\begin{array}{l}\text { (Number of series, number of selected } \\
\text { editions for a given grade) }\end{array}$ & \multicolumn{2}{|c|}{$(11,1$ to 2$)$} & \multicolumn{2}{|c|}{ (3,1 to 3$)$} & $(7,1$ to 3$)$ \\
\hline $\begin{array}{l}\text { Number of teachers' guides linked with } \\
\text { selected textbooks (gr.2, gr.3, gr.2\&3) }\end{array}$ & $(0,0,1)$ & $(0,0,0)$ & $(3,3,0)$ & $(0,2,0)$ & $(0,8,0)$ \\
\hline Treatise / other teachers' guides & 1 & & & $\begin{array}{l}1 \text { (ERMEL } \\
\text { gr.2\&3) }\end{array}$ & $\begin{array}{r}2 \text { (ERMEL } \\
\text { gr.2, gr.3) }\end{array}$ \\
\hline
\end{tabular}

In order to analyze the data, we used the following methodology. We considered the mathematics found in textbooks and syllabi for each of the five periods as an institution in the sense of the ATD framework. In general, most information related to substantiation, and many rules to be learned, are technologies, while simpler, typically procedural rules are techniques. If a solution is given for an exercise, it typically demonstrates the expected technique to be used for a significant type of tasks, or technological features of this technique. Teachers' guides and instructions provide another way to identify technologies through the explanations that are given for a task solution process.

For each period, it was necessary to identify praxeologies related to place value in order to describe the knowledge to be taught. Hence, the first step was to identify, for each syllabus and for any teacher instructions, place value themes. This, for instance, led to the inclusion of the metric system as a theme of relevance to place value in the pre-reform resources. Based on tables of contents, textbook pages that addressed place value were selected and then analyzed. Specific attention was given to three-to-four digit numbers.

For each period, the whole set of praxeologies related to numeration was reconstructed as follows. Based on textbooks and non-theoretical parts of teachers' guides, techniques to do tasks were reconstructed taking into account: 1) explicit potential indications, and 2) the most likely way to do a task according to other current tasks which could be considered as possible steps of a technique (i.e., ecological considerations). Sets of exercises were then organized into sets of tasks where the same technique was expected, thus defining types of tasks. Explanations of the techniques led to identification of technologies (referred as textbook technologies). Lastly, reference knowledge (theory) was identified through analysis of treatises and theoretical sections of 
teachers' guides. Given that such knowledge often remains implicit, an assumption was made that, in a given period, no indication meant no change related to prior period. When reference knowledge was explicit, early parts of the process of didactic transposition often became visible. In these instances, reference knowledge was explicitly used for explaining the solution process for a given task (referred as treatise technology). Analyses of textbook technologies led to establishing a set of basic rules (basic technologies) used for textbook explanations. Comparison between treatise and textbook technologies shows possible subsequent parts of the process of didactic transposition.

\section{Findings}

\subsection{Pre-reform reference knowledge}

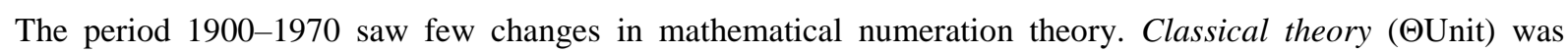
presented in the treatises by Bezout and Reynaud (1821) and closely adapted for textbooks, where it was used to support numeration and the rationale for calculation. It is based on five main rules:

- R1: Tens, hundreds, etc. can be counted as ones.

- $\quad$ R2: 10 units of a given order are equal to 1 unit of the upper order.

- R3: The amounts of units (less than ten) of each order are juxtaposed from right to left: Each place represents a unit that is ten times bigger than its right-hand neighbor. Places that are not represented are marked with the sign 0 .

- $\quad$ R4: Relations between unit names and number names. For example, as three tens are thirty and four ones are four, then three tens and four ones are thirty-four.

- $\quad$ R5: Numbers can be added, forming new numbers.

The algorithm used to build numbers provides implicit proof for the existence and uniqueness of the decomposition of a number in base ten:

1) The first ten numbers are built in sequence, starting with the unit one, then adding one to the previous number, forming the numbers one, two, etc. (R5);

2) A set of ten ones forms a new order of units: the ten (R2);

3) The tens are numbered like the ones, beginning with one ten and ending with ten tens (R1);

4) Then, the first nine numbers are added to the first nine tens: one ten, one ten and one, one ten and two [...] two tens, two tens and one, etc., forming the first ninety-nine numbers (R5);

5) The set of ten tens forms a new order of units: the hundred (R2);

6) The hundreds are numbered like the tens and the ones; from one hundred to ten hundred: one hundred, two hundred, etc. (R1);

7) Then the first ninety-nine numbers are added to the first nine hundreds forming the first nine hundred and ninety-nine numbers (R5).

Number names are presented as a literal translation (R4). Rules are stated and any exceptions are given, such as the usual name given to ten-two (dix-deux in French) is twelve (douze), the name given to nine-ten is four-twenty-ten. Last, once the numbers have been built, their positional notation is stated using (R3). 


\subsection{Reference knowledge beginning in the New Math}

New Math introduced bases, a change that, a priori, has no link with scholarly knowledge. In some teachers'

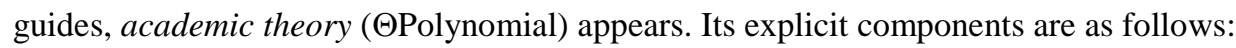

- $\quad \theta$ Poly: Existence and uniqueness of the polynomial decomposition of a number $n$ in a given base $a$ (i.e. $\left.n=\sum_{i=0}^{p} x_{i} a^{i}, 0 \leq r_{\mathbb{i}}<a\right)$.

- $\quad \theta$ Coeff: Juxtaposition of coefficients of the polynomial forms positional notation: $\left(a_{p} a_{p-1} \ldots a_{1} a_{0}\right)$.

Elements that involve reference knowledge vary, depending on teacher's guide in question, as follows:

1) Most often, classical theory was adapted: as there are no tens or hundreds in bases, unit names become generic (e.g., 'first-order unit', 'second-order unit'). Specific unit names only reappear in base ten.

2) Sometimes $\theta$ Poly is stated and formally proven using Euclidian division.

3) Base ten unit names are always present in relation to the number names, with the classical correspondence (R4).

Beginning in the 1980s, classical theory is no longer found in textbooks and teachers' guides, while at the same time $\theta$ Poly is explicitly stated. Positional notation is obtained with $\theta$ Coeff. Nowadays, $\theta$ Poly is

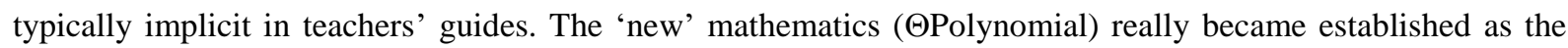
mathematical foundation for the teaching of place value during the so-called counter-reform, while there are no visible changes after this period.

The next step is to understand some long-term effects (if any) of these changes on teaching.

\subsection{A sample of praxeologies over time}

\subsubsection{A basic type of tasks: counting grouped objects}

In all periods, counting grouped objects in base ten (hereafter termed counting) appears to be a basic type of task in numeration teaching. Pre-reform, counting is always explained in terms of discrete quantities. From the 1930s, it was extended with money and continuous quantities such as length and mass based on the metric system, which became a major way to teach place value. During the New Math period, counting tasks are presented in terms of bases, with discrete and sometimes continuous quantities (Figs 3-4). Post-reform, discrete quantities persist, sometimes with the extension to money, but continuous quantities are almost never used, with length featuring in only one textbook.

The next section takes an example of a task of this type, to show the associated techniques and technologies in four different periods. There are both similarities and differences. Each technique consists of three steps and, for each period (except the New Math), techniques lead to specific, symbolic sub-techniques (step 3). These in turn create intermediate, symbolic types of task (T) - namely 'with units', multiplicative and additive decompositions - with their own techniques that require their own justification. This is typical in the ecology of knowledge.

Write the number of cubes (base ten) (from $\mathbf{T}$ : counting grouped objects)

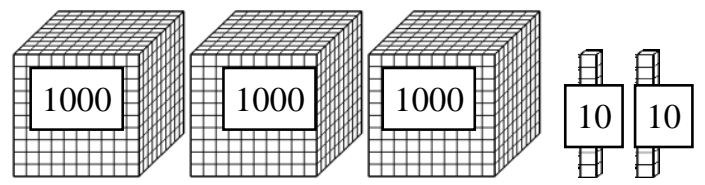




\subsubsection{Pre-reform praxeology}

\section{Technique}

Step 1) Find the total number of cubes in each kind of group: 1 thousand, 2 thousands, 3 thousands (of cubes); 1 ten, 2 tens (of cubes).

Step 2) Write the amount in units: The amount of cubes is $3 \mathrm{Th} 2 \mathrm{~T}$.

Step 3) (T: 'with units' decompositions) Write the number given by 3Th $2 \mathrm{~T}$ : Write, from left to right, thousands, then hundreds, etc.; Put zeros if required.

\section{Technology}

For step 1: R1 leads to 3Th and 2T.

For step 2: R5 leads to 3Th 2T.

For step 3: R3 (or a derived rule: the ones in the first place on the right, the tens in the second place, etc.) leads to 3020 .

Theory: $\Theta U n i t$ is used, notably the basic rules, R1, R3, R5

\subsubsection{New Math praxeology}

\section{Technique}

Step 1) Find the number of groups of each kind: 1, 2, 3 (groups of 1000); 1, 2 (groups of 10).

Step 2) Write them in the numeration chart; add any zeros that are needed.

Step 3) Take the number from the table.

\section{Technology}

The technology (only visible in the teacher's guide) is the same as pre-reform. Only one series of textbooks presents a complementary technology based on @Polynomial.

Theory: $\Theta$ Unit is used. In one instance it is juxtaposed with @Polynomial.

\subsubsection{Early post-reform praxeology}

\section{Technique}

Step 1) Find the total number of cubes in each kind of group: 1, 2, 3 groups of 1000, 1, 2 groups of 10. This corresponds to $3 \times 1000$ cubes, and $2 \times 10$ cubes.

Step 2) Write the sum: $3 \times 1000+2 \times 10$.

Step 3) (T: Multiplicative decompositions) Calculate $3 \times 1000+2 \times 10$ : Use a (mental) numeration chart, add zeros if required.

\section{Technology}

For step 1: $(\theta)$ Count one by one (up to ten), then $(\theta)$ the meaning of multiplication.

For step 2: $(\theta)$ the meaning of addition.

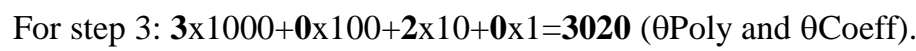




\subsubsection{Late post-reform praxeology}

One, recent textbook uses the 'early post-reform' technique, but without any technology. Other textbooks proceed as follows.

\section{Basic rules}

A set of basic rules is established. Some are typically implicit (**), while other are sometimes implicit (*), and others typically explicit. In particular, rules involving relations between two units - or two adjacent places - (R2 in $\Theta U$ Unit) are not reported as they are beyond the scope of the present study.

- $\boldsymbol{\theta}$ Algorithmic sequence: sequence of number names, one by one, ten by ten, etc.

- $\quad \theta$ Place names: ones, tens, hundreds, etc. names of the columns in the numeration chart in base ten.

- $\quad \boldsymbol{\theta}$ Name: correspondence between the positional notation and number names (in relation to $\boldsymbol{\theta}$ Place names).

- $\quad \boldsymbol{\theta}$ Additive names: $3000+20$ reads as three thousands (3000) and twenty (20), giving 3020 using $\boldsymbol{\theta}$ Name. However, this does not work for $3000+90+2$, for instance, as 3092 reads as ' 3000 ' ' 4 ' '20' ' 12 '.

- $\theta$ Count one by one.

- $\quad * \theta$ : The meaning of multiplication.

- $\quad * \theta$ : The meaning of addition.

- $\quad * * \theta$ Mult_10: Multiplication of one-digit numbers by powers of ten: $3 \times 1000=3000,2 \times 10=20$

- $\quad * \theta$ : Column addition

$$
\begin{array}{r}
3000 \\
+\quad 20 \\
\hline 3020
\end{array}
$$

- $\quad \theta$ Quantity place (in some textbooks): $3 \mathrm{Th}=3000$ (3 in the thousands column), $2 \mathrm{~T}=20$ ( 2 in the tens column) using $\boldsymbol{\theta}$ Place names.

\section{Technique}

Two techniques ( $\tau 1$ and $\tau 2)$ were identified:

Step 1) Find the total number of cubes in each kind of group.

$\tau 1)$ Count the number of cubes resulting from each kind: One thousand, two thousands, three thousands (cubes); Ten, twenty (cubes). Write each number in digits: 3000, 20.

$\tau 2)$ Count the number of each kind of group: 1, 2, 3 (groups of 1000 cubes); 1, 2 (groups of 10 cubes). Write the corresponding products: $3 \times 1000,2 \times 10$.

Step 2) Write the sum.

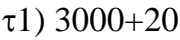
च2) $3 \times 1000+2 \times 10$ then calculate each product.

Step 3) (T: additive decompositions) Write the number given by 3000+20. (See technique, section 3.3.6).

\section{Technology}

Based on the basic rules presented above, the technologies are as follows: 
For step 1 of $\tau 1, \theta$ Algorithmic sequences then $\boldsymbol{\theta}$ Name; for step 1 of $\tau 2, \boldsymbol{\theta}$ Count one by one then $\boldsymbol{\theta}$ Meaning of multiplication.

For step 2 (of $\tau 1 \& \tau 2$ ): $\boldsymbol{\theta}$ Meaning of addition (and $\boldsymbol{\theta}$ Mult_10 for $\tau 2$ )

For step 3 (See technology, section 3.3.6).

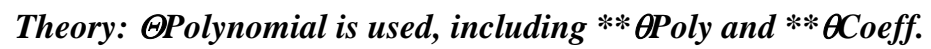

3.3.6 The praxeology of ( $T$ ) additive decompositions ('calculate: $3000+20$ ') in the late post-reform period

Technique: choose the most appropriate method from the following options,

_1) calculate by any means,

2) name,

_3) (sometimes) locate non-zero places using (T) Place names (i.e., locate the digit places): Put 3 in the 'thousands place', 2 in the 'tens place', making 3020 using a (mental) numeration chart.

\section{Technology}

For_1: $\theta$ column addition;

For_2: $\boldsymbol{\theta}$ additive name;

For_3: (sometimes) $\boldsymbol{\theta}$ Place names.

A type of task (e.g., 'what is the tens digit in the number 3020?') is used to teach place names. This may also explain the appearance of a new type of task, 'with units' decompositions, which is found in some textbooks.

3.3.7 Praxeology of (T) 'with units' decompositions ('write the number 3Th $2 \mathrm{~T}$ ') in the late post-reform period

Technique: 3 Th $2 \mathrm{~T}=3000+20$ then $3000+20=3020$ (additive decomposition).

Technology: $\boldsymbol{\theta}$ Quantity place; then technology of additive decomposition. $\boldsymbol{\theta}$ Quantity place makes it possible to link the quantity and unit name.

\subsection{Ecological interpretation}

Although the basic counting task transcends institutions, the praxeological analysis presented above shows that techniques do not. They are influenced by both theoretical and teaching considerations, notably the need for teachable technologies ( $\theta$ Poly and $\theta$ Coeff are probably not teachable). Many 'new' technologies appeared in the late post-reform period, and the situation is less clear and homogeneous than before. The basic rules are: 1) rarely fully formulated; 2) very different from reference knowledge (which is frequently invisible); and 3) inconsistent between textbooks. Unlike the pre-reform period, technologies are not derived (directly) from theory. They often correspond to pre-reform techniques, and appear as the rules that are to be used (if any) to justify techniques used to accomplish tasks. Number names appear to be a critical issue: they must be taught in 
school, but they are no longer part of academic mathematics ${ }^{3}$. They become increasingly important in technological components: e.g., $\boldsymbol{\theta}$ 'column addition' is sometimes derived from $\boldsymbol{\theta}$ 'additive names'.

\subsection{Semiotic considerations}

\subsubsection{Changes in ostensive objects over time}

The old numeration tasks - conversion and decomposition - that both use numeration units (Fig. 2) were no longer taught during the New Math. This may be due to the lack of unit names for bases other than ten (in the French language ${ }^{4}$ ). Whatever the reason, they disappeared as bases appeared. Most teaching relied on manipulatives (or their representations) and adapted numeration charts (Figs 3-4). The technique of 'counting' tasks during the New Math shows the absorption of symbolic work into ad hoc numeration charts. Polynomial decomposition was used when converting from base ten to another base (or conversely) (e.g., $13=1 \times 3 \times 3+1 \times 3+1=(111)_{3}$ is a typical type of task of the period). The consequence of the introduction of bases was that students interpreted the positional notation as a procedure (grouping, ungrouping) and struggled as soon as they did not have any manipulatives (ERMEL, 1978; Perret, 1985).

In order to overcome this difficulty, a major preoccupation of the counter-reformers was to introduce a symbolic register (ERMEL, 1978). So-called writings (e.g., $40+7+50+43+25$ ) began to appear: "The key issue is to familiarize children by working directly with writings" (ERMEL, 1978, p. 17 our translation). In the mid-1970s, there was a huge transposition of academic theory, which was largely developed and disseminated by ERMEL (1978). The process was as follows: $\sum r_{1} a^{i}$ became $\sum r_{i} 10^{i}$, then $b \times 1000+c \times 100+d \times 10+e$ or $b 000+c 00+d 0+e$. Our interpretation is as follows: the positional notation of powers of ten requires 0 and 1 as multiplicative coefficients (e.g., $100=1 \cdot \mathrm{a}^{2}+0 \cdot \mathrm{a}^{1}+0 \cdot \mathrm{a}^{0}$ ); as this is predictably difficult for early graders, these notations are given. The counter-reform syllabus shares many similarities with ERMEL (1978), and was based on writings; numeration units appeared only once (in $4^{\text {th }}$ and $5^{\text {th }}$ grades): "In 7024, there are 70 hundreds because $7024=(70 \times 100)+24 ” ;$ and bases disappeared beginning in second grade.

Among the various writings, the 'powers-of-ten written in figures' (PTWF hereafter) notation $(1 ; 10$; $100 ; 1000$, etc.) played an increasingly important role. Within a few years, standard PTWF tasks emerged that appear to be a literal translation of existing tasks from numeration unit language (Fig. 5) (e.g., 'with units' decomposition into additive decomposition). The old ostensive object numeration unit was replaced by PTWF.

\section{EXERCICES ET PROBLÈMES}

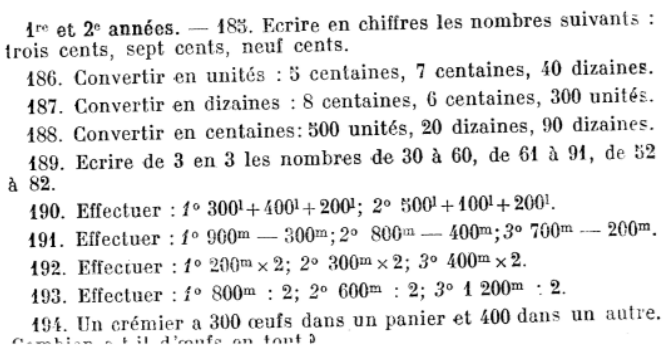

\section{EXERCISES AND PROBLEMS}

$1^{\text {st }}$ and $2^{\text {nd }}$ years. -185 . Write in digits the following numbers: three-hundred, seven-hundred, nine-hundred.

186. Convert into ones: 5 hundreds, 7 hundreds, 40 tens.

187. Convert into tens: 8 hundreds, 6 hundreds, 300 ones.

188. Convert into hundreds: 500 ones, 20 tens, 90 tens.

189. Write the numbers in steps of 3 from 30 to 60 , from 61 to

91, from 52 to 82 .

190. Calculate: $1^{\circ} 300^{1}+400^{1}+200^{1} ; 2^{\circ} 500^{1}+100^{1}+200^{1}$

191. Calculate: $900^{\mathrm{m}}-300^{\mathrm{m}} ; 800^{\mathrm{m}}-400^{\mathrm{m}} ; 3^{\circ} 700^{\mathrm{m}}-200^{\mathrm{m}}$

192. Calculate: $200^{\mathrm{m}} \times 2 ; 300^{\mathrm{m}} \times 2 ; 400^{\mathrm{m}} \times 2$

193. Calculate: $1^{\circ} 800^{\mathrm{m}}: 2 ; 2^{\circ} 600^{\mathrm{m}}: 2 ; 1200^{\mathrm{m}}: 2$

3 The early post-reform period saw an attempt to theorize based on 'number words' computations: e.g., $492=(4 \times 100)+(4 \times 20)+12$, which reads four (4) hundreds (100), four (4) twenties (20), twelve (12) (in French).

${ }^{4}$ Unlike the English language, the French language does not use the number name to form the unit name. However, working in different bases requires using several names for the unit of a given order: e.g., twos, threes, tens in the first order; fours, nines, hundreds, in the second. 
Fig. 2 Exercises from "Hundreds" (L'arithmétique au cours élémentaire, Grades 2 \& 3, 1931, p. 44) and our translation.

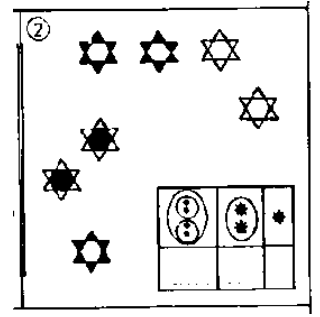

Fig. 3 Exercise from "Groupings - base 2." The statement is: "Group two by two. Write the result." (our translation) (Math et calcul, Gr. 2, 1971, p. 103)
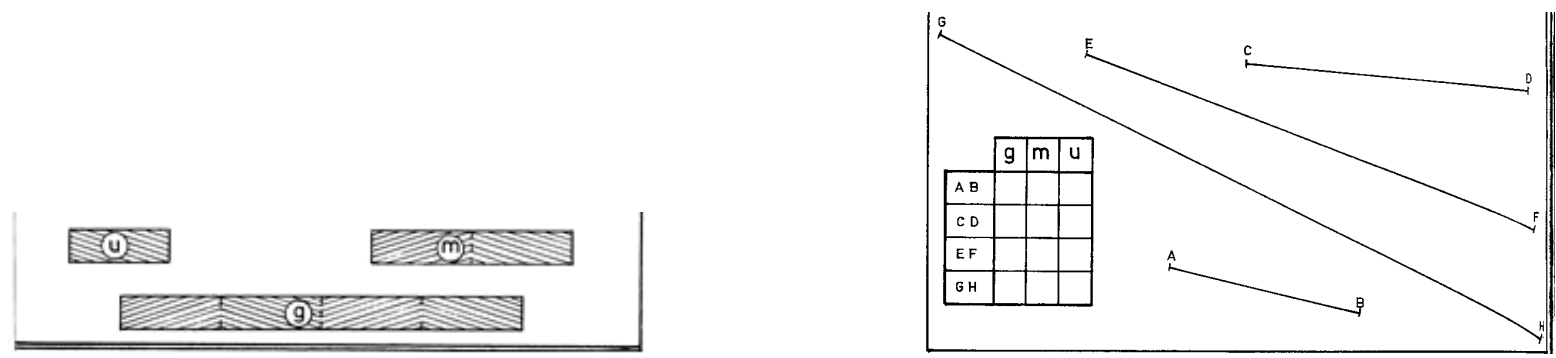

Fig. 4 Strips to cut (left) (from Math et calcul, Gr. 3, 1972, p. 143) and exercise (right) (p. 146) in "Length measures (base 2)". The statement is: "Use the base-2-strips to find the measures of the segments. Write the results in the table." (our translation) (p. 146)
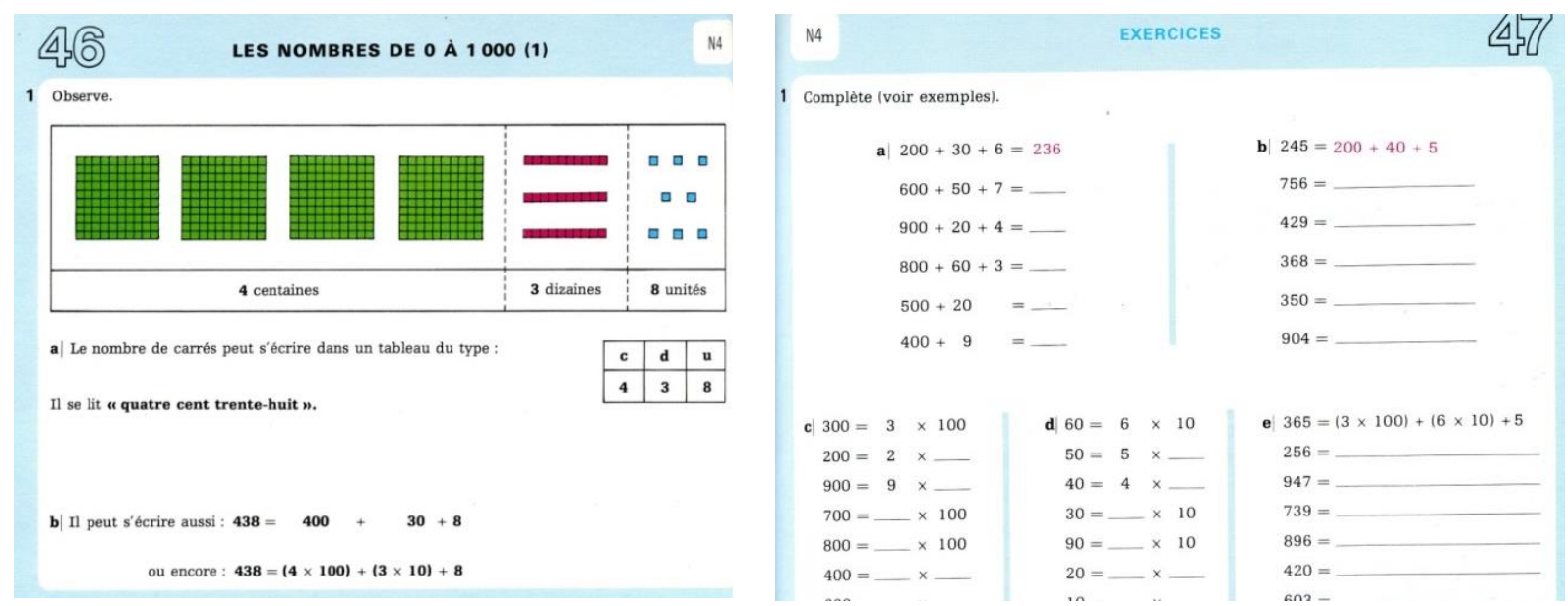

Fig. 5 Extract from "Numbers from 0 to 1000.” (Math et calcul, Grade 3, 1979, pp. 46-47)

\subsubsection{How to teach and learn place value with PTWF?}

A major technological question is how to describe positional notation within transposed academic theory, especially when a number is given in PTWF (e.g., $3 \times 100+4 \times 10+5)$. In academic theory, $\theta$ Coeff provides the answer. However, the present, typically partly implicit, rules seem to be computational ( $\theta$ Mult_10 and $\theta$ column addition). This results in the example given in Figure 6. Subsequently, when objects are grouped by powers of ten and counted as 'groups of ones' (one, two, three, etc.; ten, twenty, thirty, etc.), the link between the amount 
of groups of a given size and the corresponding digit is indirect. French number names may exacerbate the problem, and both French students and teachers struggle with it (Menotti \& Ricco, 2007; Mounier, 2013).

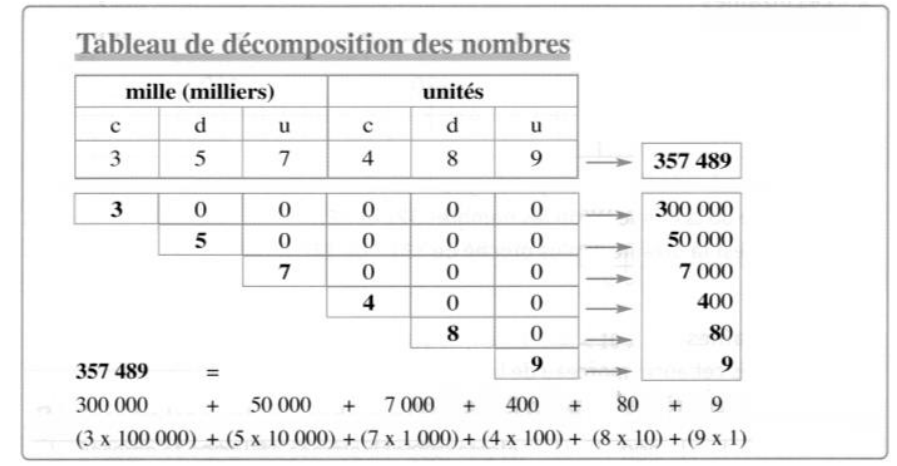

Fig. 6 “Decompose the numbers.” Extract from (Nouveau Math Elem, grade 3, 2002, p. 133)

\subsubsection{A revival of numeration units}

In ERMEL (1978) there is no symbolic work with numeration units. They become literally more frequent, and they almost always name the places of digits. It remains uncommon for textbooks of the late post-reform period to present the relation 1 hundred $=10$ tens to second- and third-grade students. This may be linked to the fact that there is no need for numeration units in academic theory.

Beginning in 1995, decomposition with numeration units reappeared (T: 'with units' decomposition in the late post-reform period) (Fig. 7). Nevertheless, the technology that is used appears to be a combination of $\theta$ Quantity place and $\theta$ column addition: $3 \mathrm{H} 4 \mathrm{~T} 5 \mathrm{O}=300+40+5=345$. This substantiation is therefore similar to that shown in Fig. 6, while this specific use of units implies that unit names have replaced the numbering of the rank of the digits that was used pre-reform. Numeration units exist in order to indicate the place of digits, rather than units: the only unit to be taught is the number " 1 ". An indication of this, is the change in the technique of 'counting grouped objects', where the cube is the only unit used post-reform, unlike the tens or hundreds of cubes that were seen pre-reform.

Observe l'exemple, puis décompose les nombres.

$$
\begin{array}{ccccc}
\multicolumn{6}{c}{648} & =600+40+8 \\
472 & 586 & 908 & 759 & 390
\end{array}
$$

Décompose les nombres en centaines, dizaines et unités selon l'exemple. $543 c^{\prime}$ est 5 centaines 4 dizaines 3 unités $\begin{array}{lllll}856 & 450 & 624 & 302 & 718\end{array}$
1) Read the example, then decompose the numbers.

$$
\begin{array}{ccccc}
\multicolumn{6}{c}{\mathbf{6 4 8}=\mathbf{6 0 0 + 4 0 + 8}} \\
472 & 586 & 908 & 759 & 390
\end{array}
$$

2) Decompose the numbers into hundreds, tens, and ones following the example.

543 is 5 hundreds 4 tens 3 ones

$\begin{array}{lllll}856 & 450 \quad 624 & 302 \quad 718\end{array}$

Fig. 7 Two exercises from "Numbers up to 999" (Pour comprendre les mathématiques, grade 3, 2002, p. 17) and our translation.

\subsubsection{The instrumental and semiotic values of numeration units}

The meaning of numeration units in praxeologies dramatically changed in the pre- and post-reform periods. Prereform they were used as units, and thus numbered. Their semiotic value was as units. Post-reform, they describe places and their semiotic value is places. They are almost never used as units in numbering quantities. 


\section{Discussion}

What can we learn from these results, taken from the French context, and restricted to the 'planned' curriculum?

\subsection{Impact of changes on what is learned}

A limitation of this study is that it only considers the first step of didactic transposition and does not consider classroom teaching. Yet, it provides some indication of what is likely and unlikely to be taught-and then learned-about decimal numeration: we found three possible interpretations of positional notation in $20^{\text {th }}$ century French textbooks:

1) With units: $456=4$ hundreds, 5 tens, and 6 ones. Here, 4 hundreds refers to 4 units in relation with tens and ones. Positional notation sums up units as: ones are in first position on the right-hand side, tens are in second position, etc. (based on classical theory).

2) Algebraic: $456=4 \times 100+5 \times 10+6$. Here, digits are coefficients of the polynomial. Positional notation sums up the algebraic relation (this originates in the transposition of academic theory).

3) Additive: $456=400+50+6$. An example is given in Fig. 6 . Here, 4 (in the hundreds column) means 4 followed by two zeros. Positional notation sums up additive relations, and the hundred is the name given to the third place. The number 1 is the only unit used (transformation of the original transposition of academic theory).

The research literature can also help. Indeed, studying another institution, Thanheiser (2009, p. 263) identified two correct conceptions of place value, and found that only 5 out of 15 pre-service teachers (in the United States) mastered one of them: the most advanced is "reference units" and the less advanced is "groups-ofones". They appear to correspond to our interpretation of 'with units' and 'additive' and Thanheiser's findings suggest that these conceptions might also have been learned by students in France. The successive transpositions suggest that the algebraic interpretation is even more difficult to teach (and learn) in elementary school.

\subsection{A tour de table of other systems}

This study focuses on the French educational system. However, New Math introduced bases in many other countries_-notably the United States (e.g., Kline, 1973)—suggesting that similar place value phenomena might have occurred. Unlike their Chinese counterparts, American teachers use "place value", a "conceptual term" (Ma, 1999, p. 34), "in a procedural way" (p. 34). They introduce the term to their students as "labels for columns where they should put numbers" (p. 34). "Conceptual" and "procedural" place value seem to correspond to our 'with units' and 'additive' interpretations. An overall theory based on the "concept of unit" (Ma, 2013, p. 1285) structures current elementary arithmetic teaching in China and Singapore (Ma, 2013). Hence, it is likely that the use of units by Chinese teachers is connected to this underlying theory. Moreover, while such theory formed the foundations of teaching in the United States before the New Math, this is no longer the case (Ma, 2013). This raises the question of the extent to which the 'additive interpretation' provided by American teachers is connected to the transposition of academic theory and the subsequent lack of units in that country. 


\subsection{An alternative to units?}

\subsubsection{Visible PTWF vs. invisible units in scholarly discourse}

In 2015, the mathematician Howe provided five stages for interpreting positional notation, and formulated various properties, with the aim of meeting the needs of elementary teaching of place value:

" $352=300+50+2$

$=3 \times 100+5 \times 10+2 \times 1$

$=3 \times(10 \times 10)+5 \times 10+2 \times 1$

$=3 \times 10^{2}+5 \times 10^{1}+2 "($ p. 109)

This first step in the transposition of academic theory uses

base ten pieces [e.g., 300, 50, 2] [that] have multiplicative structure. The first part of this structure is, the digit for each base ten piece records the number of copies of a base ten unit that is used to create that number. Thus, $300=3 \times 100,50=5 \times 10,2=2 \times 1$. The numbers 1,10 and 100 are the base ten units. (p. 108)

Base ten pieces represent amounts of units, but the role of units is not explicitly emphasized.

Both Howe (2015) and other authors such as Artigue and Robinet (1982), and Ernest (2006) refer to PTWF in teaching positional notation in elementary school. These scholars also use units (as such) as a resource to explain positional notation and students' knowledge of it. However, units do not appear as a tool in the examples they provide for students' mathematical work (if there are any).

\subsubsection{Decimal numeration: understanding units?}

The literature on place value is vast. Ross (1989) and DeBlois (1996) characterize several stages for its understanding: the relation between the places of the digits and their 'names' (ones, tens, etc.), the relation between place and an idea of magnitude, and the relation between the magnitudes of the different places. Mastering the complex decomposition of numbers such as $567=1 \mathrm{H} 34 \mathrm{~T} 127 \mathrm{O}$ requires a deep understanding of numeration (e.g., Bednarz \& Janvier, 1982; Ma, 1999; Thanheiser, 2009). Much of the literature considers the mastery of numeration units as an indication of the mastery of place value. Yet, the 'groups-of-ones' idea remains a correct conception of place value. Thompson (1999) argues additive interpretation ("quantity value", p. 186) should be taught before the 'with units' interpretation (“column value”, p. 186).

Transpositions of academic theory imply a high level of manipulation of algebraic expressions. If this has failed in France, is it mainly due to an inadequate transposition of the academic theory (maybe some properties were missing), the selection of this theory as reference knowledge, or the lack of units? What level of understanding of positional notation is achievable in elementary school, without units, or even without specific work on the semiotic system of units? Can students gain a profound understanding of place value before they have sufficiently mastered algebra? Can critical tasks - whether they are symbolic or not - involving units be identified for learning place value? Is there a mathematical theory, based on units, that is needed for students to learn units as units? Can students incidentally learn units in numeration? To what extent are the weakest students the most sensitive to the explicit teaching of units? Would these questions have different answers if the teaching language was different, e.g., with regular number names? 


\subsection{The issue of theory: towards semiotics and specific concepts}

What are the profound differences between classical and the academic theories? Numeration units, PTWF, and even monomials are examples of similar concepts that use different semiotic systems. As semiotic issues are at the core of elementary school teaching, this encourages us to revisit the work of Ernest (2006) and Otte (2011).

The successive stages of the transformation of academic theory show the growing importance of the semiotic system of PTWF, which is one way to write the numbers found in academic theory. In the context of knowledge to be taught, units are referred to as places (their semiotic value). This does not come from academic knowledge, but it enables places to be linked to number names (despite irregularities). In this example, the concept (the unit) does not appear to emerge from the teaching system if it is not already part of the current mathematical theory that is transposed. Furthermore, the sign (the names of the units) has a limited meaning (a place). Following Ernest (2006), this could help to specify the transformation of the semiotic systems in the process of didactic transposition.

Otte (2007) compares current mathematical theory to Euclidian theory, notably the question of the 'existence' of objects. The present study highlights the existence of one such object: the unit. The fundamental but naïve concept of the unit is no longer part of academic mathematics, yet it is often highlighted as a key construct in the learning of arithmetic (e.g., Lamon, 1996). In the classical treatises, the unit emerged from the theory of quantities (the semiotic value), which founded classical arithmetic (e.g., Bezout \& Reynaud, 1821). It was the fundament of numbers. While this is presently the case in China and Singapore, current academic theory - as it currently exists, for instance, in France and probably in the United States - is built on the number 1 as the only unit.

\section{Conclusion and perspectives}

This paper highlights the mathematical foundations of place value in the French curriculum, seen in syllabi and textbooks. Classical numeration theory with units seems to have provided the foundation for all tasks requiring decimal numeration prior to the New Math reform (1970). It disappeared in favor of polynomial decomposition with exponential notation. Changes in these foundations were stabilized during the counter-reform that followed the New Math.

From 1970 to 1995 , a more-or-less slow process of didactic transposition unfolded. This study highlights several steps. New tasks, notably involving manipulatives and drawings (in bases) were introduced in 1970. Old, symbolic tasks (in units) disappeared, leading to the disappearance of most work in symbolic form. Bases and the New Math ideology fostered the introduction of a new theory that implied new rationales (technologies). Bases disappeared, while new rationales evolved and were transformed into PTWF $(1,10,100$, etc.). This led to the appearance of new PTWF tasks that also met the need for symbolic techniques for working with place value. Unit names reappeared as places. The permanence of these names seems to be linked to the need to name numbers in elementary school.

In all periods, underlying theories influence the 'planned' curriculum. Indeed, theory plays a major role in providing rationales. Intermediate tasks, required to provide teachable techniques (which implies that their rationales should be accessible to students), are influenced, but not the basic tasks. Different interpretations of positional notation have appeared, in relation with different theoretical mathematical foundations. The complexity of the academic theory appears to have resulted, in the rationales of the early 2000s being heavily 
influenced by current mathematical social practice. It is likely the effects of these fundamental changes were not fully anticipated: connecting academic theory and school mathematics is a very complex undertaking, even more now than before the New Math. Classroom data are needed to study what is actually taught and learned with respect to place value. This study highlights some aspects of the French experience, and raises questions about other countries whether affected by the New Math reform or not.

A long-term, and hidden effect of the disappearance of numeration units as units is that the number 1 seems to be the only unit ${ }^{5}$ now taught. This appears to be inconsistent with a deep understanding of place value. Does the lack of numeration units impact later achievement in numeracy? Several scholars have carried out initial research into place value that highlights the positive role of base ten pieces $(3,200,5000$, etc.). Are there key tasks that require units in order to have a profound understanding of place value in early grade education? If so, what are they?

In Brazil, Moreira and David (2008) highlighted a conflict between place value content in prospective teacher training, and the mathematics needed for teaching: in the former, "a formal proof of the fact that every natural number has a unique positional representation in any base b, greater than 1" (p. 29); in the latter, e.g., "decomposition and re-grouping" (p. 28) where units are involved. We rephrase this in terms of academic theory used for training prospective teachers, and classical theory implicitly needed for teaching. Chinese teaching seems to be underpinned by foundations that appear similar to classical theory. This leads us to consider Otte's view on the axiomatics (in the sense of Euclid) that are needed to teach some concepts (Otte, 2007). The concept of the unit was the foundation of classical arithmetic — not only for numeration. At the present time, the number 1 is the only unit taught in numeration. We therefore ask, should the role of units be rethought, both in the teaching and foundations of arithmetic? Is it time to modernize classical theory?

\section{References}

Artigue, M., \& Robinet, J. (1982). Numération à l'école élémentaire. [Numeration in elementary school] Educational Studies in Mathematics, 13(2), 155-175.

Arzarello, F., \& Bartolini-Bussi, M. G. (1998). Italian trends in research in mathematics education: A national case study in the international perspective. In: J. Kilpatrick \& A. Sierpinska (Eds) Mathematics Education as a Research Domain: A Search for Identity (vol. 2), (pp. 243-262). Dordrecht: Kluwer.

Barbé, J., Bosch, M., Espinoza, L., \& Gascón, J. (2005). Didactic restrictions on the teacher's practice: The case of limits of functions in Spanish high schools. Educational Studies in Mathematics, 59, 235-268.

Bednarz, N., \& Janvier, B. (1982). The understanding of numeration in primary school. Educational Studies in Mathematics, 13(1), 33-57.

Bergé, A. (2008). The completeness property of the set of real numbers in the transition from calculus to analysis. Educational Studies in Mathematics, 67(3), 217-235.

Bezout, E., \& Reynaud, A. A. L. (1821). Traité d'arithmétique à l'usage de la marine et de l'artillerie. [Treatise of arithmetic for marine and artillery] $9^{\text {th }}$ edition.

Blanc, J.-P., Bramand, P., Debû, P., Gély, J., Peynichou, D., \& Vargas A. (2002) Pour comprendre les mathématiques. CE2. [To understanding mathematics. Grade 3] Paris: Hachette.

\footnotetext{
${ }^{5}$ Other units are taught in the context of continuous quantities such as length, mass, etc. In the context of numbers, the wording is restricted to the number 1 (and the first place in the numeration chart in French).
} 
Bosch, M., \& Chevallard, Y. (1999). La sensibilité de l'activité mathématique aux ostensifs: objet d'étude et problématique. [Sensitivity to ostensive objects in doing mathematics: object of study and research problem] Recherches en didactique des mathématiques, 19(1), 77-123.

Bosch, M., Gascón, J., \& Trigueros, M. (2017). Dialogue between theories interpreted as research praxeologies: the case of APOS and the ATD. Educational Studies in Mathematics, 95(1), 39-52.

Boucheny, G., \& Guérinet, A. (1931) L'arithmétique au cours élémentaire. [Arithmetic in the $2^{\text {nd }}$ and $3^{\text {rd }}$ grades] Paris: Larousse

Bronner, A. (2008). La question du numérique dans l'enseignement du secondaire. [The numeric issue in secondary teaching] In: A. Rouchier \& I. Bloch (Eds.) Perspectives en didactique des mathématiques (pp.1745). Grenoble: La pensée sauvage.

Bruner, J. S. (1966). Toward a theory of instruction. Harvard University Press.

Castela, C., \& Romo Vázquez, A. (2011). Des mathématiques à l'automatique : étude des effets de transposition sur la transformée de Laplace dans la formation des ingénieurs. [From mathematics to automation: study of effects of transposition on Laplace transform in engineering education] Recherches en didactique des mathématiques, 31(1), 79-130.

Chambris, C. (2008). Relations entre les grandeurs et les nombres dans les mathématiques de l'école primaire. [Relations between quantities and numbers in mathematics for elementary school] Thesis. Paris: Université Paris-Diderot.

Chambris, C. (2010). Relations entre grandeurs, nombres et opérations dans les mathématiques de l'école primaire au 20e siècle: théories et écologie. [Relations between quantities, numbers and operations in mathematics for elementary school in the $20^{\text {th }}$ century: theories and ecology] Recherches en didactique des mathématiques, 30(3), 317-366.

Chevallard, Y. (1985). La transposition didactique. [Didactic transposition] Grenoble: La pensée sauvage.

Chevallard, Y. (1997). Familière et problématique, la figure du professeur. [The teacher as a colloquial and problematic figure] Recherches en didactique des mathématiques, 17(3), 17-54.

Deblois, L. (1996). Une analyse conceptuelle de la numération de position au primaire. [A conceptual analysis of numeration in elementary school] Recherches en didactique des mathématiques, 16(1), 71-127.

Eiller, R., Brini, R., Martineu, M., Ravenel, S. \& Ravenel, R. (1979) Math et calcul. CE2. [Math and computation. Grade 3]. Paris: Hachette

Eiller, R., \& Martineu, M. (1972) Math et calcul. CE2. [Math and computation. Grade 3]. Paris: Hachette

Eiller, R., Martineu, M., Brini, R., Cornibé, R., \& Pradillon F. (1971) Math et calcul. CE1. [Math and computation. Grade 2]. Paris: Hachette

ERMEL (1978). Apprentissages mathématiques à l'école élémentaire. Cycle élémentaire. (Vol. 2). [Mathematical learning in elementary school. Second and third grades. Vol. 2.] Paris: SERMAP-Hatier.

Ernest, P. (2006). A semiotic perspective of mathematical activity: The case of number. Educational Studies in Mathematics, 61(1-2), 67-101.

Freudenthal, H. (1973). Mathematics as an educational task. Dordrecht: Reidel.

Furinghetti, F., Menghini, M., Arzarello, F., \& Giacardi, L. (2008). ICMI renaissance: The emergence of new issues in mathematics education. In: M. Menghini et al. (Eds.), The first century of the International 
Commission on Mathematical Instruction (1908-2008). Reflecting and shaping the world of mathematics education (pp. 131-147). Rome, Italy: Istituto della Enciclopedia Italiana.

Fuson, K. C. (1990). Conceptual structures for multiunit numbers: Implications for learning and teaching multidigit addition, subtraction, and place value. Cognition and Instruction, 7(4), 343-403.

Gispert, H. (2010). Rénover l'enseignement des mathématiques, la dynamique internationale des années 1950. [Renewing mathematics teaching, the international dynamic of the 1950s] In: R. d'Enfert \& P. Kahn (Eds), En attendant la réforme. Politiques éducatives et disciplines scolaires sous la Quatrième République (pp. 131-143). Grenoble: PUG

Griesel, H. (2007). Reform of the construction of the number system with reference to Gottlob Frege. ZDM, 39(1-2), 31-38.

Harlé, A. (1987). L'image du nombre dans les manuels d'arithmétique de l'enseignement primaire au début du $\mathrm{XX}^{\text {ème }}$ siècle. [Image of numbers in arithmetic textbooks from early $20^{\text {th }}$ century] In: Groupe d'Histoire des Mathématiques (Eds.) Fragments d'histoire des mathématiques II. (pp. 22-84). Paris: APMEP.

Howe, R. (2015). The most important thing for your child to learn about arithmetic. In: X. Sun, B. Kaur, \& J. Novotná (Eds.) Proceedings of the twenty-third ICMI study: Primary mathematics study on whole numbers. (pp. 107-114) China, Macao: University of Macao

ICMI (2014) Discussion document of the twentythird ICMI study: Primary mathematics study on whole numbers. Retrieved from http://www.mathunion.org/fileadmin/ICMI/docs/ICMIStudy23_DD.pdf

Kilpatrick, J. (2012). The new math as an international phenomenon. ZDM, 44(4), 563-571.

Kline, M. (1973). Why Johnny can't add: the failure of the new math. New York: St. Martin's Press.

Lamon, S. J. (1996). The development of unitizing: Its role in children's partitioning strategies. Journal for Research in Mathematics Education, 27(2), 170-193.

Ma, L. (1999). Knowing and teaching elementary mathematics: Teachers' understanding of fundamental mathematics in China and the United States. Mahwah, NJ: Lawrence Erlbaum Associates.

Ma, L. (2013). A critique of the structure of U.S. elementary school mathematics. Notices of the AMs, 60(10), 1282-1296.

Menotti, G., \& Ricco, G. (2007). Didactic practice and the construction of the personal relation of six-year-old pupils to an object of knowledge: Numeration. European Journal of Psychology of Education, 22(4), 477495.

Moreira, P. C., \& David, M. M. (2008). Academic mathematics and mathematical knowledge needed in school teaching practice: Some conflicting elements. Journal for Mathematics Teacher Education, 11(1), 23-40.

Mounier, E. (2013). Y a-t-il des marges de manœuvres pour piloter la classe durant une phase de bouclage? [Is there a degree of latitude for the teacher when he ends the lesson?] Recherches en didactique des mathématiques, $33(1), 79-113$.

Neyret, R. (1995). Contraintes et détermination des processus de formation des enseignants : nombres décimaux, rationnels et réels dans les Instituts Universitaires de Formation des Maîtres. [Constraints and determinations of teacher education: decimals, rational and real numbers in training institutes] Thèse. Grenoble: Université Joseph Fourier - Grenoble1.

Otte, M. F. (2007). Mathematical history, philosophy and education. Educational Studies in Mathematics, 66(2), $243-255$. 
Otte, M. F. (2011). Evolution, learning, and semiotics from a Peircean point of view. Educational Studies in Mathematics, 77(2-3), 313-329.

Perret, J. F. (1985). Comprendre l'écriture des nombres. [Understanding written numerals] Bern: P. Lang.

Ross, S. H. (1989). Parts, wholes and place value: A developmental view. Arithmetic Teacher, 36(6), 47-51.

Thanheiser, E. (2009). Preservice elementary school teachers' conceptions of multidigit whole numbers. Journal for Research in Mathematics Education, 40(3), 251-281.

Thompson, I. (1999). Implications of research on mental calculations for the teaching of place value. Curriculum, 20(3), 185-191.

Wittmann, E. (1975). Natural numbers and groupings. Educational Studies in Mathematics, 6(1), 53-75. 